\title{
Egyptian practical guidance in hypertriglyceridemia management 2021
}

\author{
Hesham Salah El Din Taha 1*, Hossam Kandil ${ }^{1}$, Nabil Farag², Abbas Oraby³, Magdy El Sharkawy², \\ Fouad Fawzy ${ }^{1}$, Hossam Mahrous ${ }^{1}$, Juliette Bahgat ${ }^{1}$, Mina Samy ${ }^{1}$, Mohamed Aboul ${ }^{1}$, Mostafa Abdrabou ${ }^{1}$ and \\ Mirna Mamdouh Shaker ${ }^{1}$
}

\begin{abstract}
Hypertriglyceridemia (HTG) is a very common, yet underappreciated problem in clinical practice. Elevated triglyceride (TG) levels are independently associated with atherosclerotic cardiovascular disease (ASCVD) risk. Furthermore, severe HTG may lead to acute pancreatitis. Although LDL-guided statin therapy has improved ASCVD outcomes, residual risk remains. Recent trials have demonstrated that management of high TG levels, in patients already on statin therapy, reduces the rate of major vascular events. Few guidelines were issued, providing important recommendations for HTG management strategies. The goal of treatment is to reduce the risk of ASCVD and acute pancreatitis. The management stands on lifestyle modification, detection of secondary causes of HTG and pharmacological therapy, when indicated. In this guidance we review the causes and classification of HTG and summarize the current methods for risk estimation, diagnosis and treatment. The present guidance provides a focused update on the management of HTG, outlined in a simple user-friendly format, with an emphasis on the latest available data.
\end{abstract}

Keywords: Hypertriglyceridemia, Dyslipidemia, Practical guidance, Atherosclerotic cardiovascular disease

\section{Background}

Hypertriglyceridemia (HTG) prevalence in adults varies between 10 and $29 \%$ according to the studied population [1]. HTG is classified as primary; due to genetic causes, or may be secondary to particular diseases, drugs or metabolic disorders [2].

Dyslipidemia itself usually causes no symptoms but can lead to symptomatic vascular disease, including coronary artery disease (CAD), cerebrovascular disease and peripheral arterial disease (PAD). In hereditary lipid disorders, a patient may present with the variants of cutaneous xanthoma. Eruptive xanthomas at pressure sites on the elbows, buttocks, and knees may be indicative of hypertriglyceridemia. High levels of TG $(>500 \mathrm{mg} / \mathrm{dL})$ can cause acute pancreatitis. Higher TG levels can also

\footnotetext{
*Correspondence: heshsalt@yahoo.com

${ }^{1}$ Department of Cardiology, Faculty of Medicine, Cairo University, 27

Nafezet Sheem El Shafae St Kasr Al Ainy, Cairo 11562, Egypt

Full list of author information is available at the end of the article
}

cause dyspnea, hepatosplenomegaly lipemia retinalis and neurological manifestations such as confusion, transient memory loss, paresthesias and rarely, focal neurologic deficits. Extremely high lipid levels also give a lactescent (milky) appearance to blood plasma [3-5].

HTG is an underappreciated risk factor that is often overshadowed by low-density lipoprotein cholesterol (LDL-C) and other chronic conditions [6]. Studies have shown that despite the use of statin therapy, atherosclerotic cardiovascular disease (ASCVD) event rates remain high in patients with elevated TG [7]. The importance of lowering plasma levels of TG is currently considered an integral part of residual cardiovascular risk reduction strategies [8]. The American College of Cardiology/ American Heart Association cholesterol guidelines list HTG as a risk-enhancing factor for cardiovascular disease (CVD) [9].

Dietary TGs are carried via the intestinal lymphatics in chylomicrons, while endogenous TGs produced by the liver are transported in very low density 
lipoproteins (VLDL) [10]. Large triglyceride-rich lipoproteins (TRL) particles such as nascent chylomicrons are unable to infiltrate the vessel wall [11]. However, cholesteryl-ester (CE)-enriched smaller TRLs ('remnants') can penetrate the subendothelium promoting atherogenesis through pro-inflammatory and prothrombotic pathways [12].

Therefore, ASCVD risk mediated by TRLs appears to be determined by the circulating concentration of apo B-containing particles rather than their TG content. An estimate for all apo B-containing lipoproteins is non-HDL-C [calculated as total cholesterol (TC) - HDL-C], hence its importance [13].

In addition, HTG is frequently associated with pathological high-density lipoprotein (HDL) particles that may add to the ASCVD risk [12].

Furthermore, HTG is believed to be causative in up to $10 \%$ of episodes of acute pancreatitis [14]. The risk of acute pancreatitis is a continuum with mild hypertriglyceridemia associated with a low long-term risk $[15,16]$, while more severe HTG is associated with progressively increased risk $[16,17]$.

We have previously published a consensus statement on the management of lipids [18]. We felt that there was a need to address an ignored and frequently overlooked part in the management of dyslipidemia which was hypertriglyceridemia. The following guidance is based on the best scientific evidence available till present and expert opinion considerations.

\section{Scope of the article}

The goal of this article is to provide practical guidance for clinicians in situations not covered by the current lipid guidelines, in a world with rapidly evolving evidence.

There are current gaps in care for high-risk patients with mild to moderate as well as severe forms of HTG. There are also limited data on management of patients at low to moderate atherosclerotic cardiovascular risk and moderately elevated triglycerides.

The evidence from clinical trials on triglyceride riskbased agents for ASCVD risk reduction is evolving and newer medications are soon coming into play. In this document, we aim to fulfill the following aspects:

1. Definition and categories of HTG

2. Role of lifestyle intervention in patients with HTG

3. Role of statin therapy in patients with HTG

4. Triglyceride risk-based non-statin therapies; when and how to give them?

5. Providing practical algorithms for HTG management

\section{Definitions and classifications}

Hypertriglyceridemia is defined as a fasting plasma/ serum TG level $>150 \mathrm{mg} / \mathrm{dL}$ or a non-fasting TG level $>175 \mathrm{mg} / \mathrm{dL}$. We endorse the definition proposed by the American College of Cardiology on persistent hypertriglyceridemia; Fasting triglycerides $\geq 150 \mathrm{mg} / \mathrm{dL}$ following a minimum of 4-12 weeks of lifestyle intervention, a stable dose of maximally tolerated statin therapy when indicated, as well as evaluation and management of secondary causes of hypertriglyceridemia [7].

Patients with HTG can be categorized according to their fasting TG level as shown in Table 1.

\section{Causes of hypertriglyceridemia}

HTG may be either secondary to a variety of medical conditions or medications, or primary due to genetic causes [2]. Potential secondary causes for hypertriglyceridaemia [7] are listed in Table 2.

While secondary factors more frequently cause mild to moderate HTG, severe forms of HTG are more commonly primary in nature [10]. The causes of primary HTG are listed in Table 3 [19-22].

\section{Who and when should we screen?}

The age at which screening is recommended differs according to the level of risk as illustrated in Table 4.

Screening for HTG should also be considered in patients with [7]:

- Acute pancreatitis

- Suspected primary HTG:

- Presence of tuberous xanthomas in the patient or family member

- Family history of HTG

- Severely elevated TG levels

- Premature ASCVD in the patient or family member

- Secondary causes for HTG

Table 1 Categories of hypertriglyceridemia and goals of therapy

\begin{tabular}{lll}
\hline Category of HTG & $\begin{array}{l}\text { Fasting TG } \\
\text { level }(\mathbf{m g} / \mathbf{d l})\end{array}$ & Goals \\
\hline Mild & $150-199$ & $\begin{array}{l}\text { Reduce ASCVD risk and risk of } \\
\text { pancreatitis }\end{array}$ \\
Moderate & $200-499$ & \\
Severe & $\geq 500$ & \\
Very severe & $\geq 1000$ & \\
\hline
\end{tabular}


Table 2 Secondary causes of hypertriglyceridemia

Secondary causes of hypertriglyceridemia [7]:

Diseases

Metabolic and dietary disorders

Drugs

Pregnancy
Uncontrolled diabetes mellitus, chronic kidney disease, nephrotic syndrome, hypothyroidism, Cushing's disease Overweight/obesity, metabolic syndrome, sedentary lifestyle, alcohol abuse or alcohol excess, diets high in saturated fat, sugar, or high-glycemic index foods, total parenteral nutrition with lipid emulsions

Propofol, beta blockers, diuretics, thiazide and loop diuretic agents, bile acid sequestrants, glucocorticosteroids, anabolic steroids, oral estrogens, tamoxifen, HIV protease inhibitors, atypical antipsychotics, tacrolimus, sirolimus, cyclosporine, interferons

Table 3 Different types of familial HTG [19-22]

\begin{tabular}{|c|c|c|c|c|c|}
\hline & $\begin{array}{l}\text { FCH } \\
\text { (Type IIB) }\end{array}$ & $\begin{array}{l}\text { FCS } \\
\text { (Type I) }\end{array}$ & $\begin{array}{l}\text { MFCS } \\
\text { (Type IV) }\end{array}$ & $\begin{array}{l}\text { FHTG } \\
\text { (Type V) }\end{array}$ & $\begin{array}{l}\text { FD } \\
\text { (Type III) }\end{array}$ \\
\hline Lipoprotein change & $\uparrow V L D L, L D L$ & $\uparrow$ Chylomicrons & $\uparrow V L D L$ & $\uparrow V L D L$, chylomicrons & $\uparrow I D L$ \\
\hline Lipid change & $\uparrow T G, T C$ & 个TG & $\uparrow T G$ & $\uparrow T G, T C$ & $\uparrow T G, T C$ \\
\hline Incidence & $1 / 100-200$ & $1 / 500,000-1,000,000$ & $1 / 600-1000$ & $1 / 500$ & $1 / 10,000$ \\
\hline Genetics & $\begin{array}{l}\text { Polygenic (TG, LDL raising } \\
\text { alleles) }\end{array}$ & $\begin{array}{l}\text { Monogenic } \\
\text { homozygous (auto- } \\
\text { somal recessive) }\end{array}$ & $\begin{array}{l}\text { Monogenic heterozygous } \\
\text { (autosomal dominant) }^{\mathrm{a}} \\
\text { Polygenic }\end{array}$ & $\begin{array}{l}\text { Monogenic heterozygous } \\
\text { (autosomal dominant) }^{\mathrm{a}} \\
\text { Polygenic }\end{array}$ & $\begin{array}{l}\text { Monogenic } \\
\text { homozygous } \\
\text { (defect in APOE } \\
\text { gene) }\end{array}$ \\
\hline Time of presentation & \multicolumn{5}{|c|}{ All in adulthood (earlier with secondary causes) except for FCS (type I) in childhood } \\
\hline Specific for diagnosis & $\begin{array}{l}\text { Combination of: } \\
\text { ApoB }>120 \mathrm{mg} / \mathrm{dL} \\
\text { TGs }>133 \mathrm{mg} / \mathrm{dL} \\
\text { FH of premature CVD }\end{array}$ & $\begin{array}{l}\text { TG }>885 \text { mg/dl } \\
\text { Creamy appearance } \\
\text { of the blood } \\
\text { Failure to thrive, } \\
\text { Recurrent abdomi- } \\
\text { nal pain, nausea, } \\
\text { vomiting } \\
\text { Acute pancreatitis } \\
\text { (60-80\% lifetime } \\
\text { risk) } \\
\text { Tuberous xanthoma } \\
\text { Lipemia retinalis } \\
\text { Hepatospleno- } \\
\text { megaly }\end{array}$ & $\begin{array}{l}\text { TG } 150-885 \mathrm{mg} / \mathrm{dl} \\
\text { or } \\
>885 \mathrm{mg} / \mathrm{dl} \text { with second- } \\
\text { ary insult } \\
\text { Responsive to standard } \\
\text { therapy } \\
\text { Require an aggravating } \\
\text { effect }\end{array}$ & $\begin{array}{l}\text { TG } 150-885 \text { mg/dl } \\
\text { Require an aggravating } \\
\text { effect } \\
\text { Lower risk of pancreatitis }\end{array}$ & $\begin{array}{l}\text { Palmer crease } \\
\text { xanthomas } \\
\text { are pathogno- } \\
\text { monic }\end{array}$ \\
\hline
\end{tabular}

FCH familial combined hyperlipidemia, FCS familial chylomicronemia syndrome, FD familial dysbetalipoproteinaemia, FHTG familial HTG, GPIHBP1 glycosylphosphatidylinositol-anchored high-density lipoprotein binding protein-1, MFCS multifactorial chylomicronemia syndrome, $L D L$ low density lipoprotein, $L M F 1$ Lipase maturation factor 1, LPL lipoprotein lipase, TC total cholesterol, TG TG, VLDL very low-density lipoprotein, FH family history

a Defect in LPL, APOC2, APOA5, GPIHBP1 or LMF1 genes

Table 4 Recommendations for screening [18]

Primary prevention

Secondary prevention

Family history of early CVD or familial As early as the second year of life dyslipidemia

\section{How should we screen?}

For screening, lipid testing should include total cholesterol (TC), low-density lipoprotein cholesterol (LDL-C), high-density lipoprotein cholesterol (HDL-C), TG and
non-HDL-C. It can generally be done using a non-fasting blood sample. The postprandial rise in TG is usually small, between 12 and $27 \mathrm{mg} / \mathrm{dL}$. Fasting lipid testing is preferred in patients with metabolic syndrome, family history of premature ASCVD or genetic lipid disorders, non-fasting $\mathrm{TG} \geq 400 \mathrm{mg} / \mathrm{dL}$ and to assess adherence to lifestyle interventions and lipid lowering medications [7, $9,18,23,24]$.

\section{Management of HTG in patients without ASCVD or diabetes mellitus (DM)}

Limited data are available on ASCVD risk reduction using TG risk-based non-statin therapies for primary prevention in non-diabetic patients with persistent 
mild to moderate HTG [7]. Management of these patients is described in Fig. 1. However, patients with more severe forms of HTG have a relatively higher incidence of acute pancreatitis [7]. Management of these patients is described in Fig. 2.

\section{Management of HTG in patients with ASCVD}

Individuals with persistent moderate to severe HTG may be at increased risk of premature CVD. Few studies have shown an independent relationship, although small, between HTG and CVD. Studies have suggested that the ApoB-containing particles and/or lipoprotein (a), rather than the TG content of TRLs and their remnants are the cause of ASCVD risk [25, 26]. Management of HTG in ASCVD patients is illustrated in Fig. 3.

\section{Management of HTG in patients with DM}

The leading cause of mortality in diabetes mellitus is CVD. Diabetic patients have higher risk of developing ASCVD and much of this risk can be attributed to the development of atherogenic dyslipidemia, in which HTG is an essential component.

In well-controlled DM, the lipid profile may be normal, while in poorly controlled DM, the lipid profile shows a triad of HTG, increased levels of small dense LDL, and low HDL [27]. The management algorithm of HTG in diabetic patients is shown Figs. 2 and 4.

\section{Management of HTG in patients with chronic kidney disease (CKD)}

HTG is frequently encountered in the setting of CKD, especially in association with nephrotic syndrome and in patients on peritoneal dialysis [28]. The exact mechanisms through which CKD causes HTG are not exactly known, however, increased catabolism of VLDL [due to increased lipoprotein lipase (LPL) inhibitors as apo-C III] and increased VLDL production have been suggested [29]. Risk factors for development of HTG in CKD include DM, the degree of glomerular filtration rate (GFR) affection, severity of proteinuria, the modality of renal replacement therapy (peritoneal dialysis more than hemodialysis), nutritional status of the patient, and the presence of other comorbidities [14].

The aim of treatment is to primarily reduce the patient's cardiovascular $(\mathrm{CV})$ risk and in patients with severe HTG, reduce the risk of pancreatitis [14]. Nonpharmacological treatment is indicated as in patients without CKD, but diet modification is not recommended in malnourished patients. Statins are the cornerstone of treatment and are recommended to all patients with nondialysis-dependent stage 3 or higher CKD, or recipients of renal transplantation. They should not be started in dialysis-dependent patients but should be continued if already on statins before being dialysis-dependent [23]. Caveats of statin use in CKD include the need for dose adjustment of some statins and the higher risk of rhabdomyolysis when used with cyclosporine or fibrates [11]. Icosapent Ethyl should be considered if HTG persists on statin therapy [30]. Whether there is a net benefit

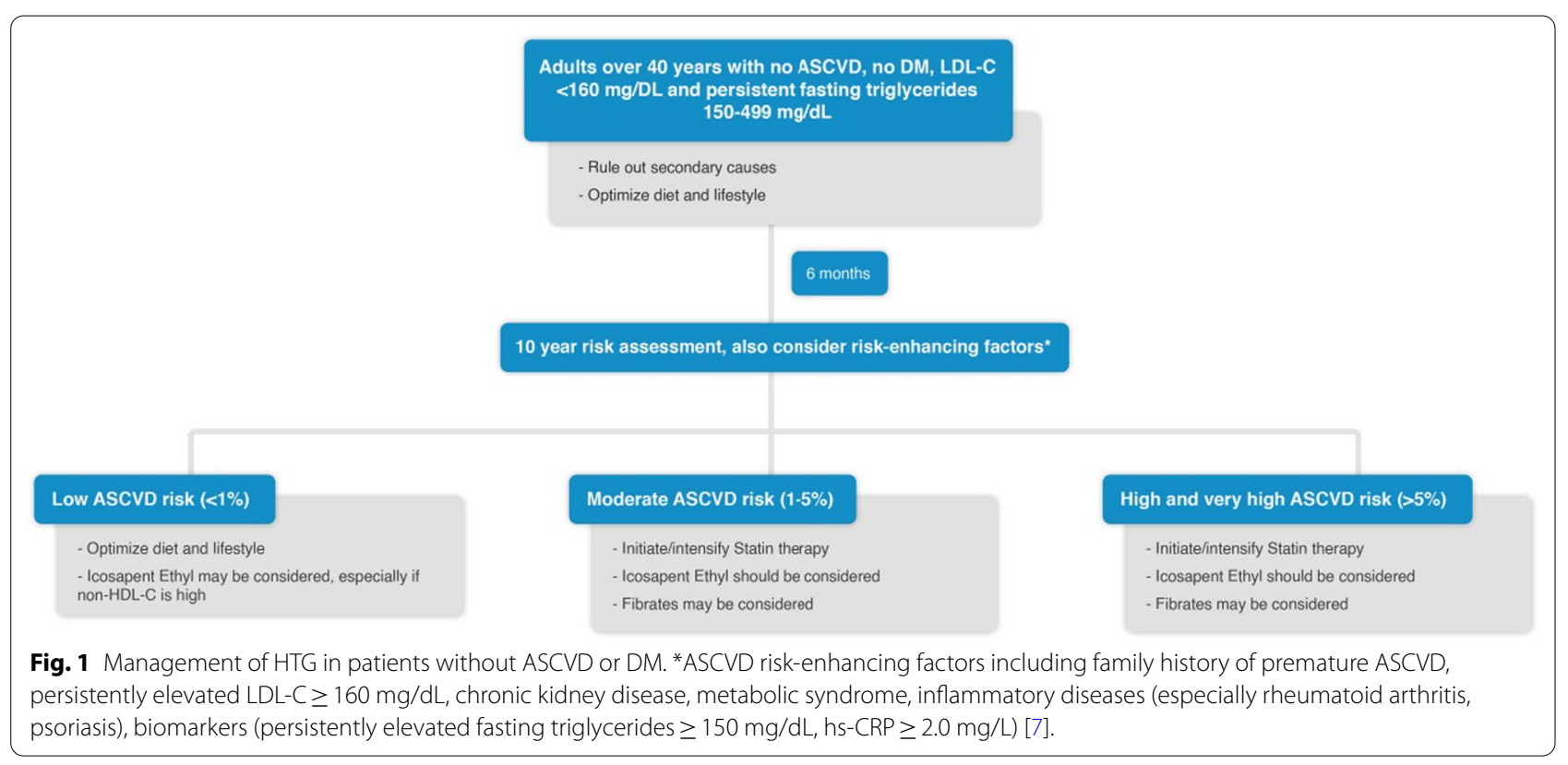




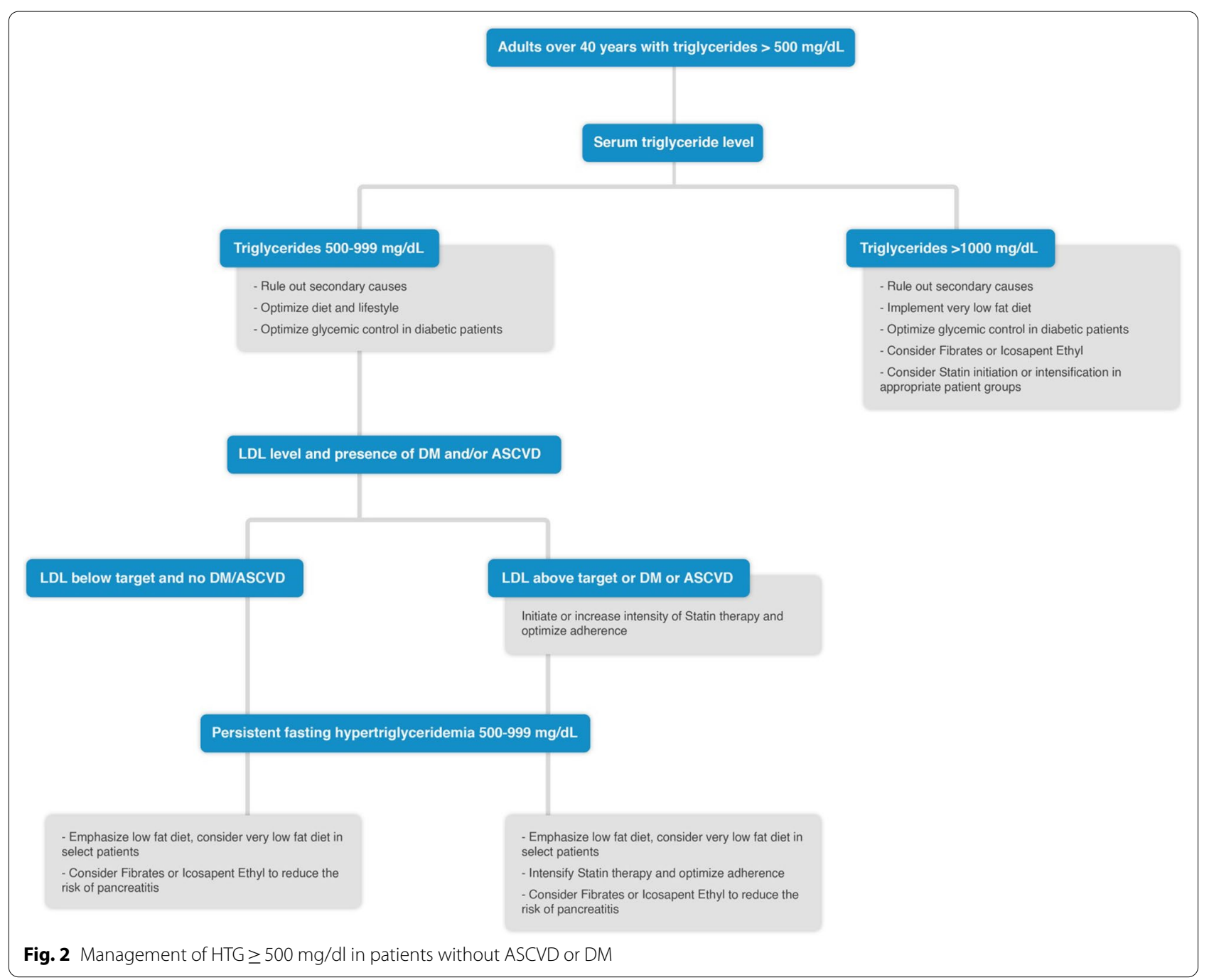

or not on CV outcomes with fibrate use in CKD is still unknown. Fibrates are therefore not recommended for the reduction of CV risk in CKD patients [14]. They may be considered in patients with severe HTG who are at high risk of pancreatitis under specialist consultation. Fibrates should be adjusted to GFR. Fibrates may lower cyclosporine levels in patients with renal transplants [14]. Lomitapide may be considered in patients with severe HTG who are at high risk of pancreatitis, with dose adjustment to GFR [31].

\section{Management of HTG in patients with familial hypertriglyceridemia (FHTG)}

There are five different types of FHTG classified according to the type of elevated lipoprotein and associated lipid changes including: familial combined hyperlipidemia $(\mathrm{FCH})$, which is the commonest, familial chylomicronemia syndrome (FCS), familial dysbetalipoproteinaemia
(FD), familial HTG (FHTG), and multifactorial chylomicronemia syndrome (MFCS) (Table 3) [19-22].

Pharmacologic management is frequently needed in FHTG to prevent pancreatitis and/or reduce risk of CVD. Medications commonly used for TG lowering are icosapent ethyl, fibrates, and Niacin [32]. In individuals who are unresponsive to treatment, plasmapheresis has been used.

There has been considerable interest in developing new TG lowering agents, especially for treatment of FHTG, using approaches targeting LPL and its regulators because of the central role they play in TRL metabolism. Volanesorsen is an antisense oligonucleotide that binds to apolipoprotein C3 (APOC3) mRNA preventing APOC3 translation. It has been shown to lower circulating APOC3 levels by $70-90 \%$ and TG levels by $56-86 \%$ in clinical trials involving both FCS and non-FCS patients with moderate to severe HTG. A reduction in the number of episodes of pancreatitis was also reported. The 


\section{Adults with ASCVD and fasting triglycerides 150-499 mg/dL}

- Rule out secondary causes

Optimize diet and lifestyle

- Optimize glycemic control

- Intensify Statin therapy (preferably high intensity) and optimize adherence

\section{Persistent fasting hypertriglyceridemia $150-499 \mathrm{mg} / \mathrm{dL}$}

\section{LDL-C $<55 \mathrm{mg} / \mathrm{dL}$}

- Icosapent Ethyl should be considered

- Fibrates may be considered

Check LDL-C level

\section{Persistent fasting hypertriglyceridemia 150-499 mg/dL}

- Icosapent Ethyl should be considered

- Fibrates may be considered

Fig. 3 Management of HTG in patients with ASCVD

monoclonal antibody evinacumab that blocks the action of angiopoietin-like protein 3 (ANGPTL3) has been found to lower TG levels up to $80 \%$ in patients with mild to moderate HTG, as well as LDL-C levels [33, 34].

\section{Lifestyle interventions}

HTG is closely associated with a sedentary lifestyle and visceral adiposity. Weight loss is considered the most effective lifestyle intervention to lower TG levels; the effect of weight loss on lowering TGs is variable [35]. Five to ten percent reduction in body weight is associated with a $20 \%$ decrease in TG [34]. Higher-fat, lower carbohydrate diets have better effect on TG levels compared with lower-fat, higher carbohydrate diets [36]. The reduction in TG was greater for the very low carbohydrate regimens (in which carbohydrates represent $<10 \%$ of calories) [37]. A higher-protein (31\% of caloric intake) versus a standard-protein (18\% of caloric intake) weightloss diet results in more weight loss and TG lowering [38].

There are different types of fasting, as shown in Table 5 . Weight loss and greater TG lowering were noticed with alternate day fasting. A summary of nutrition recommendations for patients with HTG is shown in Table 6. 


\section{Adults over 40 years with DM, no ASCVD, and fasting triglycerides $150-499 \mathrm{mg} / \mathrm{dL}$ \\ - Rule out secondary causes \\ Optimize diet and lifestyle \\ - Optimize glycemic control \\ - Intensify Statin therapy (preferably high intensity) and optimize adherence}

Persistent fasting hypertriglyceridemia $150-499 \mathrm{mg} / \mathrm{dL}$

Shared decision making, consider the patient's preference Icosapent Ethyl or Fibrates may be considered according to the presence of other ASCVD risk factors and the degree of elevation of TGs

Fig. 4 Management of HTG in diabetic patients without ASCVD

Alcohol is an important cause of elevated TG levels; patients with HTG are advised to abstain completely.

Physical activity and exercise reduce TG levels by $7-30 \%$; the response is variable depending on the type, duration, and intensity of activity. In addition, smoking cessation should be advocated as a part of lifestyle intervention.

\section{Pharmacological management [32]}

Classes of medications commonly used in the management of HTG include omega-3 fatty acids, fibric acid derivatives and niacin. High doses of a strong statin (simvastatin, atorvastatin, rosuvastatin) also lower TG by up to $30 \%$. The effect of different drugs on different lipid components is illustrated in Table 7.

\section{Fibrates [39]}

Fibrates are commonly used to treat HTG. They increase the activity of LPL through peroxisome proliferator activated receptor (PPAR) alpha receptor agonist action, which hydrolyzes TG in TRL.

Fibrates may be associated with a reversible increase in serum creatinine; therefore the dose should be lowered in patients with mild-to-moderate renal disease (about one third of the usual dose) and should be avoided in severe renal impairment. Risk for myopathy/ rhabdomyolysis increases with renal impairment or concurrent use of HMG-CoA reductase inhibitors. Rarely, severe anemia, leukopenia, thrombocytopenia may occur so periodic blood counts are recommended.

Table 5 Types of fasting [34-38]

\begin{tabular}{ll}
\hline Alternate day fasting & $\begin{array}{l}3 \text { to } 4 \text { days/week, consumption of }<25 \% \text { of energy needs } \\
\text { during a } 24-h \text { period }\end{array}$ \\
Periodic fasting & Fasting 1 or 2 days/week \\
Time restricted eating & Food intake is limited to a specific window of time each day
\end{tabular}

Table 6 Summary of nutrition recommendations for patients with HTG [7, 34-38]

\begin{tabular}{|c|c|c|c|}
\hline Nutrient & Encourage & Limit/restrict & Stop completely \\
\hline Sugar-sweetened beverages & & IfTG $<500$ mg/dl & If TG > $500 \mathrm{mg} / \mathrm{dl}$ \\
\hline Fruits & $\begin{array}{l}\text { Can be included but individualize } \\
3-4 \text { servings per day }\end{array}$ & 1 serving per day if TG > 1000 & \\
\hline Vegetables & Encourage most vegetables & $\begin{array}{l}\text { Vegetables with high glycemic } \\
\text { index (carrots, potatoes,..) }\end{array}$ & $\begin{array}{l}\text { Canned vegetables } \\
\text { Vegetable juices }\end{array}$ \\
\hline Legumes & Encourage & & \\
\hline Fish—sea food & $\begin{array}{l}\text { Encourage fatty or lean fish at least } 2 \\
\text { servings/week }\end{array}$ & & \\
\hline Poultry-lean meats & Encourage instead of red meat & & \\
\hline Dairy products & & Limit full-fat dairy & $\begin{array}{l}\text { Sugar-sweetened dairy products } \\
\text { Full fat dairy if TG> } 1000 \text { mg/dl }\end{array}$ \\
\hline Fiber-rich whole grains & Encourage 4-6 servings per day & & \\
\hline Nuts and peanuts & Encourage in moderation & Limit if TG > 1000 mg/dl & \\
\hline Desserts & & $\begin{array}{l}\text { May be used occasionally if TG } \\
500-999 \text { mg/dl }\end{array}$ & Avoid if TGs > 1000 mg/dl \\
\hline
\end{tabular}


Table 7 Lipid effects of different drugs:

\begin{tabular}{|c|c|}
\hline Drug & Lipid effects \\
\hline Fenofibrate & $\begin{array}{l}\text { LDL } \downarrow: 20.6 \% \text { (145 mg) } \\
\mathrm{HDL} \uparrow: 11 \%(145 \mathrm{mg}) \\
\mathrm{TG} \downarrow: 23.5-50.6 \% \text { (greatest drop is in } \\
\text { patients with highest TG) (145 mg) }\end{array}$ \\
\hline IPE & $\begin{array}{l}\mathrm{HDL} \uparrow: 9.1 \%(4 \mathrm{~g} / \text { day }) \\
\mathrm{TG} \downarrow: 45 \% \text { (4 g/day) }\end{array}$ \\
\hline Niacin & $\begin{array}{l}\text { LDL } \downarrow: 14-17 \%(2 \mathrm{~g} / \text { day }) \\
\text { HDL } \uparrow: 22-26 \%(2 \mathrm{~g} / \text { day }) \\
\text { TG } \downarrow: 20-50 \%\end{array}$ \\
\hline Ezetimibe & $\begin{array}{l}\text { LDL } \downarrow: 18 \%(10 \mathrm{mg} / \text { day }) \\
\text { HDL } \uparrow: 1 \%(10 \mathrm{mg} / \text { day }) \\
\text { TG } \downarrow: 8 \%\end{array}$ \\
\hline Statins & $\begin{array}{l}\text { LDL } \downarrow: 30-50 \% \text { (dose, and drug dependent) } \\
\text { HDL } \uparrow: 1-10 \% \\
\text { TG } \downarrow: 10-30 \%\end{array}$ \\
\hline
\end{tabular}

\section{Omega 3 fatty acids [40]}

Icosapent ethyl and docosahexaenoic acid (DHA) are the active constituents of the omega 3 fatty acids. Higher doses of icosapent ethyl (2-4 g) significantly reduce the levels of TGs. Omega 3 fatty acids reduce hepatic VLDL-TG synthesis and secretion. They also increase plasma LPL activity that in turn enhances TG clearance from circulating VLDL particles. Caution should be exercised in patients allergic to fish. Recurrent atrial fibrillation or flutter has been reported with administration of high doses. Omega 3 fatty acids may increase liver alanine transaminase (ALT), therefore it should be monitored. They may prolong bleeding time; therefore, caution is needed in patients at high bleeding risk.

\section{Niacin [32]}

Niacin reduces VLDL synthesis, and may increase chylomicron TG removal from plasma. Caution is used in patients with gout, DM, gall bladder disease, CVD, renal or hepatic impairment, if the patient is taking anticoagulants or HMG-CoA reductase inhibitors or if symptoms of myopathy occur (monitor creatine phosphokinase).

\section{Statins [32]}

Statins are competitive inhibitors of the activity of HMG-CoA reductase enzyme. This results in the reduction of the levels of LDL. Statins reduce TG possibly through upregulation of the VLDL uptake by hepatocytes, as well as a reduction in the production rate of VLDLs. Statin-associated muscle symptoms (SAMs) may occur in $10-15 \%$. Liver function tests should be checked at baseline, and when clinically indicated.

\section{Conclusions}

Management algorithms proposed in this document for the management of hypertriglyceridemia are simple, cover the clinical situations most commonly observed in routine practice and are designed to improve the quality of care. In all patients with HTG, risk stratification is mandatory and an attempt should be made to identify a cause or association. All patients with HTG should have an assessment of their LDL-C and non-HDL-C levels. The goal of therapy is to reduce ASCVD risk, as well as risk of pancreatitis. The first step of treatment involves implementing lifestyle changes and management of secondary causes, if present. Proper control of other ASCVD risk factors is recommended. Statins are advised as first line agent for ASCVD risk reduction. For patients with persistently elevated TG levels after non-pharmacologic interventions and despite maximally tolerated LDLguided therapy, we suggest introducing additional drug therapy when indicated. Pharmacological management in persistent, as well as severe HTG, is centered on omega-3 fatty acid therapy and fenofibrate.

\section{Future directions}

HTG and its impact on ASCVD remain an underexplored frontier in lipidology. Research is needed to uncover the molecular basis and the dynamics of the different atherogenic particles in this disease process.

A risk stratification algorithm for acute pancreatitis in patients with severe HTG is needed.

More RCT-based evidence is needed for the use of fibrates to reduce $\mathrm{CV}$ risk in various subgroups e.g.: $\mathrm{CKD}$ patients and the elderly.

More data regarding the efficacy of IPE in reducing $\mathrm{CV}$ risk without concomitant statin use (e.g.: in patients intolerant to statins) is needed.

Further safety and efficacy data on novel drugs acting on existing pharmacological targets (e.g.: the novel selective PPAR alpha modulator-pemafibrate), or novel pharmacological targets (e.g.: apoC-III and ANGPTL-3) is needed.

\footnotetext{
Abbreviations

ACC: American College of Cardiology; ANGPTL3: Angiopoietin-like protein 3; ApoB: Apolipoprotein-B; ApoC: Apolipoprotein-C; ASCVD: Atherosclerotic cardiovascular disease; CAD: Coronary artery disease; CE: Cholesteryl-ester; CKD: Chronic kidney disease; CV: Cardiovascular; CVD: Cardiovascular disease; CYP2CA: Cytochrome-P 2CA; DGAT: Diacylglycerol acyltransferase; DM: Diabetes mellitus; FCH: Familial combined hyperlipidemia; FCS: Familial chylomicronemia syndrome; FD: Familial dyslipoproteinemia; FHTG: Familial hypertriglyceridemia; GFR: Glomerular filtration rate; GPIHBP1: Glycosylphosphatidylinositol-anchored high density lipoprotein binding protein-1; HDL-C: High density lipoprotein-cholesterol; HIV: Human immunodeficiency virus; HMG-CoA: Hydroxymethylglutaryl coenzyme-A; Hs-CRP: Highlysensitive C-reactive protein; HTG: Hypertriglyceridemia; IDL-C: Intermediate density lipoprotein-cholesterol; IPE: Icosapent ethyl; LDL-C: Low density
} 
lipoprotein-cholesterol; LMF1: Lipase maturation factor 1; LPL: Lipoprotein lipase; MCT: Medium-chain triglyceride; MFCS: Multifactorial chylomicronemia syndrome; mRNA: Messenger ribonucleic acid; PPAR: Peroxisome proliferator activated receptor; PTT: Partial thromboplastin time; SAM: Statin-associated muscle symptom; SPPARMa: Selective PPAR alpha modulator;T1DM: Type-1 diabetes mellitus; T2DM: Type-2 diabetes mellitus; TC: Total cholesterol; TG: Triglyceride; TRL: Triglyceride-rich lipoprotein; VLDL-C: Very low density lipoprotein-cholesterol.

\section{Acknowledgements}

None.

\section{Authors' contributions}

HT: main author, put the idea behind this review and wrote, revised and edited the manuscript. HK, NF, AO, MS, FF, HM, JB, MS, ME, MA, MM: contributed to the writing of this manuscript and has read and approved the final manuscript.

\section{Funding}

None.

\section{Availability of data and materials}

The dataset supporting the results and conclusions of this article will be available from the corresponding author on request.

\section{Declarations}

\section{Ethics approval and consent to participate}

This research involved human subjects and was performed in accordance with the Declaration of Helsinki and approved by Cairo University Ethical Committee with reference number-Egypt.

\section{Consent for publication}

Not applicable.

\section{Competing interests}

No conflict of interest.

\section{Author details}

'Department of Cardiology, Faculty of Medicine, Cairo University, 27 Nafezet Sheem El Shafae St Kasr Al Ainy, Cairo 11562, Egypt. ${ }^{2}$ Ain-Shams University, Cairo, Egypt. ${ }^{3}$ Suez Canal University, Ismailia, Egypt.

Received: 24 August 2021 Accepted: 14 December 2021

Published online: 20 December 2021

\section{References}

1. Karpov $Y$, Khomitskaya Y (2015) PROMETHEUS: an observational, crosssectional, retrospective study of hypertriglyceridemia in Russia. Cardiovasc Diabetol 14(1):1-14. https://doi.org/10.1186/S12933-015-0268-2

2. Chait A, Subramanian S (2000) Hypertriglyceridemia: pathophysiology, role of genetics, consequences, and treatment

3. Dyslipidemia - endocrine and metabolic disorders-MSD manual professional edition. https://www.msdmanuals.com/professional/endoc rine-and-metabolic-disorders/lipid-disorders/dyslipidemia. Accessed 14 Nov 2021

4. Goyal A, Cusick AS, Bansal P. Familial Hypertriglyceridemia. StatPearls. Published online July 4, 2021. https://www.ncbi.nlm.nih.gov/books/NBK55 6024/. Accessed 14 Nov 2021

5. Nayak KR, Daly RG (2004) Images in clinical medicine. Eruptive xanthomas associated with hypertriglyceridemia and new-onset diabetes mellitus. N Engl J Med 350(12):1235-1235. https://doi.org/10.1056/NEJMICM030676

6. Elkhal I, Warden BA (2021) Clinical considerations for the management of hypertriglyceridemia. Am Fam Phys 103(6):325-326

7. Virani SS, Morris PB, Agarwala A et al (2021) 2021 ACC expert consensus decision pathway on the management of ASCVD risk reduction in patients with persistent hypertriglyceridemia. J Am Coll Cardiol. https:// doi.org/10.1016/J.JACC.2021.06.011

8. Vrablík M, Češka R (2015) Treatment of hypertriglyceridemia: a review of current options. Physiol Res 64(Suppl 3):S331-S340. https://doi.org/10. 33549/PHYSIOLRES.933199

9. Grundy SM, Stone NJ, Bailey AL et al (2019) 2018 AHA/ACC/AACVPR/ AAPA/ABC/ACPM/ADA/AGS/APhA/ASPC/NLA/PCNA guideline on the management of blood cholesterol: executive summary: a report of the American College of Cardiology/American Heart Association Task Force on Clinical Practice Guidelines. J Am Coll Cardiol 73(24):3168-3209. https://doi.org/10.1016/j.jacc.2018.11.002

10. Laufs U, Parhofer KG, Ginsberg HN, Hegele RA (2020) Clinical review on triglycerides. Eur Heart J 41(1):99-109c. https://doi.org/10.1093/eurhe artj/ehz785

11. Nordestgaard BG, Stender S, Kjeldsen K (1988) Reduced atherogenesis in cholesterol-fed diabetic rabbits. Giant lipoproteins do not enter the arterial wall. Arteriosclerosis. https://doi.org/10.1161/01.atv.8.4.421

12. Hegele RA, Ginsberg HN, Chapman MJ et al (2014) The polygenic nature of hypertriglyceridaemia: implications for definition, diagnosis, and management. Lancet Diabetes Endocrinol. https://doi.org/10.1016/S22138587(13)70191-8

13. Ference BA, Kastelein JJP, Ray KK et al (2019) Association of triglyceridelowering $L P L$ variants and LDL-C-lowering LDLR variants with risk of coronary heart disease. JAMA J Am Med Assoc. https://doi.org/10.1001/ jama.2018.20045

14. Tonelli MA, Wanner C, Cass A et al (2013) Kidney Disease: Improving Global Outcomes (KDIGO) lipid work group. KDIGO clinical practice guideline for lipid management in chronic kidney disease. Kidney Int Suppl 3(3):1-315

15. Yang AL, McNabb-Baltar J (2020) Hypertriglyceridemia and acute pancreatitis. Pancreatology. https://doi.org/10.1016/j.pan.2020.06.005

16. Hypertriglyceridemia-UpToDate. https://www.uptodate.com/contents/ hypertriglyceridemia. Accessed 20 Aug 2021.

17. Scherer J, Singh VP, Pitchumoni CS, Yadav D (2014) Issues in hypertriglyceridemic pancreatitis: an update. J Clin Gastroenterol. https://doi.org/10. 1097/01.mcg.0000436438.60145.5a

18. Taha HSED, Badran HM, Kandil H et al (2021) Egyptian practical guidance in lipid management 2020. Egypt Hear J. https://doi.org/10.1186/ s43044-021-00140-1

19. Dron JS, Hegele RA (2020) Genetics of hypertriglyceridemia. Front Endocrinol (Lausanne). https://doi.org/10.3389/FEND0.2020.00455

20. Chyzhyk V, Brown AS (2020) Familial chylomicronemia syndrome: a rare but devastating autosomal recessive disorder characterized by refractory hypertriglyceridemia and recurrent pancreatitis. Trends Cardiovasc Med. https://doi.org/10.1016/j.tcm.2019.03.001

21. Shah AS, Wilson DP (2015) Primary hypertriglyceridemia in children and adolescents. J Clin Lipidol. https://doi.org/10.1016/j.jacl.2015.04.004

22. Hassing HC, Surendran RP, Mooij HL, Stroes ES, Nieuwdorp M, DallingaThie GM (2012) Pathophysiology of hypertriglyceridemia. Biochim Biophys Acta Mol Cell Biol Lipids. https://doi.org/10.1016/j.bbalip.2011.11. 010

23. Mach F, Baigent C, Catapano AL et al (2020) 2019 ESC/EAS Guidelines for the management of dyslipidaemias: lipid modification to reduce cardiovascular risk. Eur Heart J 41(1):111-188. https://doi.org/10.1093/eurhe artj/ehz455

24. Langsted A, Freiberg JJ, Nordestgaard BG (2008) Fasting and nonfasting lipid levels influence of normal food intake on lipids, lipoproteins, apolipoproteins, and cardiovascular risk prediction. Circulation. https:// doi.org/10.1161/CIRCULATIONAHA.108.804146

25. Khetarpal SA, Rader DJ (2015) Triglyceride-rich lipoproteins and coronary artery disease risk: new insights from human genetics. Arterioscler Thromb Vasc Biol. https://doi.org/10.1161/ATVBAHA.114.305172

26. Wang H, Eckel RH (2009) Lipoprotein lipase: from gene to obesity. Am J Physiol Endocrinol Metab. https://doi.org/10.1152/ajpendo.90920.2008

27. Hartz JC, de Ferranti S, Gidding S (2018) Hypertriglyceridemia in diabetes mellitus: implications for pediatric care. J Endocr Soc. https://doi.org/10. 1210/js.2018-00079

28. Kwan BCH, Kronenberg F, Beddhu S, Cheung AK (2007) Lipoprotein metabolism and lipid management in chronic kidney disease. J Am Soc Nephrol. https://doi.org/10.1681/ASN.2006091006 
29. Dušejovská M, Vecka M, Rychlík I, Žák A (2020) Dyslipidemia in patients with chronic kidney disease: etiology and management. Vnitr Lek. https:// doi.org/10.36290/vnl.2020.082

30. Vijayaraghavan K, Szerlip HM, Ballantyne CM et al (2019) Icosapent ethyl reduces atherogenic markers in high-risk statin-treated patients with stage 3 chronic kidney disease and high triglycerides. Postgrad Med. https://doi.org/10.1080/00325481.2019.1643633

31. Alonso R, Cuevas A, Mata P (2019) Lomitapide: a review of its clinical use, efficacy, and tolerability. Core Evid. https://doi.org/10.2147/ce.s174169

32. Davidson MH, Toth PP (2004) Comparative effects of lipid-lowering therapies. Prog Cardiovasc Dis. https://doi.org/10.1016/j.pcad.2004.04.007

33. Cruz-Bautista I, Huerta-Chagoya A, Moreno-Macías H et al (2021) Familial hypertriglyceridemia: an entity with distinguishable features from other causes of hypertriglyceridemia. Lipids Health Dis. https://doi.org/10.1186/ s12944-021-01436-6

34. Goldberg RB, Chait A (2020) A comprehensive update on the chylomicronemia syndrome. Front Endocrinol (Lausanne). https://doi.org/10. 3389/fendo.2020.593931

35. Byrne A, Makadia S, Sutherland A, Miller M (2017) Optimizing non-pharmacologic management of hypertriglyceridemia. Arch Med Res. https:// doi.org/10.1016/j.arcmed.2017.11.017

36. Jensen MD, Ryan DH, Apovian CM et al (2013) AHA/ACC/TOS guideline for the management of overweight and obesity in adults: a report of the American College of cardiology/American Heart Association task force on practice guidelines and the obesity society. Circulation. https://doi.org/ 10.1161/01.cir.0000437739.71477.ee

37. Fechner E, Smeets ETHC, Schrauwen P, Mensink RP (2020) The effects of different degrees of carbohydrate restriction and carbohydrate replacement on cardiometabolic risk markers in humans-a systematic review and meta-analysis. Nutrients. https://doi.org/10.3390/nu12040991

38. Wycherley TP, Moran L, Clifton PM, Noakes M, Brinkworth GD (2012) Effects of energy-restricted high-protein, low-fat compared with standard-protein, low-fat diets: a meta-analysis of randomized controlled trials. Am J Clin Nutr. https://doi.org/10.3945/ajcn.112.044321

39. Elam MB, Ginsberg HN, Lovato LC et al (2017) Association of fenofibrate therapy with long-term cardiovascular risk in statin-treated patients with type 2 diabetes. JAMA Cardiol. https://doi.org/10.1001/jamacardio.2016. 4828

40. Picard F, Bhatt DL, Ducroca G et al (2019) Generalizability of the REDUCEIT trial in patients with stable coronary artery disease. J Am Coll Cardiol. https://doi.org/10.1016/j.jacc.2019.01.016

\section{Publisher's Note}

Springer Nature remains neutral with regard to jurisdictional claims in pub-

lished maps and institutional affiliations.

\section{Submit your manuscript to a SpringerOpen ${ }^{\circ}$ journal and benefit from:}

- Convenient online submission

- Rigorous peer review

- Open access: articles freely available online

- High visibility within the field

- Retaining the copyright to your article

Submit your next manuscript at $\gg$ springeropen.com 